\title{
Forewarned Is Forearmed: Can Better Patient Counseling Increase MRI Utilization in High-Risk Women?
}

\author{
Amy E. Cyr, MD', and Ranjna Sharma, $\mathrm{MD}^{2}$ \\ ${ }^{1}$ Washington University School of Medicine, St. Louis, MO; ${ }^{2}$ Upstate Specialty Services, Harrison Center, Syracuse, NY
}

The American Cancer Society, National Comprehensive Cancer Network, American Society of Breast Surgeons, and American College of Radiology (ACR $)^{1-5}$ recommend supplemental breast cancer screening with magnetic resonance imaging (MRI) for high-risk women, defined as having $\geq 20 \%$ lifetime risk of breast cancer. ${ }^{6-8}$

Although dependent on technical factors, clinical indications, and radiologist experience, the high sensitivity of MRI makes it a useful screening modality: ${ }^{9}$ Its sensitivity is $70-100 \%$ in high-risk populations, notably better than that of mammography alone. ${ }^{6,7,9,10}$ MRI detects cancers earlier, when they are smaller and node negative — and thus lower stage —and it is especially good at identifying aggressive invasive cancers. ${ }^{5,8,11-15}$ Many MRI-detected cancers are still mammographically occult, ${ }^{8,10}$ so incorporation of screening MRI may reduce the interval cancer rate to $<1 \%$. ${ }^{6,7}$

Despite these advantages, only a minority of eligible women undergo screening MRI. Even among mutation carriers, uptake rates are low. ${ }^{6},{ }^{16-18}$ So why are not more high-risk women pursuing MRI?

MRI has well-described drawbacks: first, screening MRI does not clearly improve mortality; ${ }^{6}$ it is expensive and may be physically uncomfortable; some patients are concerned about cumulative gadolinium exposure and deposition; ${ }^{19}$ and finally, specificity is lower than that of mammography, and high-risk patients may already be

(C) Society of Surgical Oncology 2020

First Received: 6 July 2020

Accepted: 8 July 2020;

Published Online: 9 August 2020

A. E. Cyr, MD

e-mail: amycyr@gmail.com anxious about developing breast cancer, with any false positives and subsequent tests possibly heightening that anxiety.

In this issue, Coopey et al. review a cohort of patients from their high-risk breast clinic. ${ }^{20}$ They identified women with lifetime risk $\geq 20 \%$ using the Gail and Tyrer-Cuzick models, excluding those with known germline mutations. Patients in this dedicated clinic had excellent uptake of screening MRI: two-thirds of the 282 patients evaluated during the clinic's first year pursued the recommended MRI.

Like other investigators, however, Coopey et al. note the low specificity of MRI. Almost a quarter of their patients required further evaluation of MRI findings with additional imaging and/or biopsy. As in other studies, most of these MRI findings were benign on core biopsy and not clinically actionable. ${ }^{9,20}$

Interestingly, Coopey et al. identified only two new breast cancers with MRI, equaling a cancer detection rate of $1 \%$. In literature, cancer detection rates with screening MRI range from $0.8 \%$ to $39 \%,{ }^{10-12,17}$ with variability due to study indication and underlying patient risk. Several investigators, for instance, report better cancer yield in women with genetic predisposition, high-risk lesions, or a personal history of breast cancer, compared with patients whose lifetime risk is $\geq 20 \%$ only because of a modest family cancer history. ${ }^{7,9,17,21}$ As the authors note, further study of this topic can outline which patient populations will benefit most from screening MRI.

As patients accumulate more MRI's over time, comparisons can be made with prior studies, which improves accuracy ${ }^{9}$ and the false-positive rate. ${ }^{12,22}$ Specificity can be further optimized by performing the MRI during days 7-14 of a premenopausal patient's cycle, which reduces background enhancement. ${ }^{8,9}$ 
Screening breast MRI is unanimously recommended for high-risk women, so we should encourage its use. It is especially important for younger women and women with genetic predisposition to cancer. ${ }^{23-27}$ In fact, the ACR offers annual MRI alone as an alternative to MRI plus mammography for BRCA1 carriers under age $40 !^{5,23,27}$

We agree wholeheartedly with the authors on the importance of counseling patients that false positives are common, especially on first MRIs. ${ }^{20,21}$ Patients can be reassured that callbacks become less common with additional rounds of screening. Forewarned is forearmed, and appropriate counseling can minimize patient anxiety and improve patient acceptance of screening breast MRI.

DISCLOSURE We have no financial interests related to this topic or manuscript.

\section{REFERENCES}

1. American Cancer Society Recommendations for the Early Detection of Breast Cancer. https://www.cancer.org/cancer/brea st-cancer/screening-tests-and-early-detection/american-cancer-so ciety-recommendations-for-the-early-detection-of-breast-cancer. html. Accessed June 25, 2020.

2. Bevers TB, Helvie M, Bonaccio E, et al. NCCN Clinical Practice Guidelines in Oncology: Breast Cancer Screening and Diagnosis version 1.2019. https://www.nccn.org/professionals/physician_gl s/pdf/breast-screening.pdf. Accessed June 26, 2020.

3. Daly MB, Pilarski R, Berry MP, et al. NCCN Clinical Practice Guidelines in Oncology: Genetic/Familial High-Risk Assessment: Breast, Ovarian, and Pancreatic, version 1.2020. https:// www.nccn.org/professionals/physician_gls/pdf/genetics_bop.pdf. Accessed June 26, 2020.

4. American Society of Breast Surgeons. Consensus guideline on diagnostic and screening magnetic resonance imaging of the breast. https://www.breastsurgeons.org/docs/statements/Consens us-Guideline-on-Diagnostic-and-Screening-Magnetic-Resonanc e-Imaging-of-the-Breast.pdf. Accessed June 26, 2020.

5. Monticciolo DL, Newell MS, Moy L, Niell B, Monsees B, Sickles EA. Breast cancer screening in women at higher-thanaverage risk: recommendations from the ACR. $J$ Am Coll Radiol 2018;15(3):408-14.

6. Niell BL, Freer PE, Weinfurtner RJ, Arleo EK, Drukteinis JS. Screening for breast cancer. Radiol Clin North Am. 2017;55(6):1145-1162. https://doi.org/10.1016/j.rcl.2017.06.004.

7. Sippo DA, Burk KS, Mercaldo SF, et al. Performance of screening breast MRI across women with different elevated breast cancer risk indications. Radiology. 2019;292(1):51-9. h ttps://doi.org/10.1148/radiol.2019181136.

8. Mann RM, Cho N, Moy L. Breast MRI: State of the art. Radiology. 2019;292(3):520-36. https://doi.org/10.1148/radiol. 2019182947.

9. Mann RM, Balleyguier C, Baltzer PA, et al. Breast MRI: EUSOBI recommendations for women's information. Eur Radiol. 2015;25(12):3669-78. https://doi.org/10.1007/s00330-015-3807$\mathrm{z}$.

10. Nakashima K, Uematsu T, Harada TL, et al. MRI-detected breast lesions: clinical implications and evaluation based on MRI/ultrasonography fusion technology. Jpn $J$ Radiol. 2019;37(10):685-93. https://doi.org/10.1007/s11604-019-008668.
11. Kriege M, Brekelmans CT, Boetes C, et al. Efficacy of MRI and mammography for breast-cancer screening in women with a familial or genetic predisposition. $N$ Engl $J$ Med. 2004;351(5):427-37. https://doi.org/10.1056/NEJMoa031759.

12. Berg WA, Zhang Z, Lehrer D, et al. Detection of breast cancer with addition of annual screening ultrasound or a single screening MRI to mammography in women with elevated breast cancer risk. JAMA. 2012;307(13):1394-404. https://doi.org/10.1001/ja ma.2012.388.

13. Warner E, Hill K, Causer P, et al. Prospective study of breast cancer incidence in women with a BRCA1 or BRCA2 mutation under surveillance with and without magnetic resonance imaging. J Clin Oncol. 2011 May 1;29(13):1664-9.

14. Bakker MF, de Lange SV, Pijnappel RM, et al. Supplemental MRI screening for women with extremely dense breast tissue. $N$ Engl J Med 2019; 381:2091-102.

15. Sung JS, Stamler S, Brooks J, et al. Breast cancers detected at screening MR imaging and mammography in patients at high risk: method of detection reflects tumor histopathologic results. Radiology. 2016;280(3):716-22. https://doi.org/10.1148/radiol. 2016151419.

16. Miles R, Wan F, Onega TL, et al. Underutilization of supplemental magnetic resonance imaging screening among patients at high breast cancer risk. J Womens Health (Larchmt). 2018;27(6):748-54. https://doi.org/10.1089/jwh.2017.6623.

17. Yu J, Park A, Morris E, Liberman L, Borgen PI, King TA. MRI screening in a clinic population with a family history of breast cancer. Ann Surg Oncol. 2008;15(2):452-61. https://doi.org/10. 1245/s10434-007-9622-2.

18. Stout NK, Nekhlyudov L, Li L, et al. Rapid increase in breast magnetic resonance imaging use trends from 2000 to 2011. JAMA Intern Med. 2014;174(1):114-21.

19. Sardanelli F, Cozzi A, Trimboli RM, Schiaffino S. Gadolinium retention and breast MRI screening: more harm than good? AJR Am J Roentgenol. 2020;214(2):324-7. https://doi.org/10.2214/A JR.19.21988.

20. Laws A, Mulvey $\mathrm{T}$, Jalbert N, et al. Baseline screening MRI uptake and findings in women with $\geq 20 \%$ lifetime risk of breast cancer. Ann Surg Oncol. 2020. https://doi.org/10.1245/s10434020-08853-4.

21. Vreemann S, Gubern-Merida A, Schlooz-Vries MS, et al. Influence of risk category and screening round on the performance of an MR imaging and mammography screening program in carriers of the BRCA mutation and other women at increased risk. $R a-$ diology. 2018;286(2):443-51.

22. Kriege M, Brekelmans CT, Boetes C, et al. Differences between first and subsequent rounds of the MRISC breast cancer screening program for women with a familial or genetic predisposition. Cancer. 2006;106(11):2318-26. https://doi.org/10.1002/cncr. 21863.

23. Obdeijn IM, Winter-Warnars GA, Mann RM, Hooning MJ, Hunink MG, Tilanus-Linthorst MM. Should we screen BRCA1 mutation carriers only with MRI? A multicenter study. Breast Cancer Res Treat. 2014;144(3):577-82. https://doi.org/10.1007/ s10549-014-2888-8.

24. Mann RM, Kuhl CK, Moy L. Contrast-enhanced MRI for breast cancer screening. J Magn Reson Imaging. 2019;50(2):377-90. h ttps://doi.org/10.1002/jmri.26654.

25. Kuhl C, Weigel S, Schrading S, et al. Prospective multicenter cohort study to refine management recommendations for women at elevated familial risk of breast cancer: The EVA trial. $J$ Clin Oncol 2010;28(9):1450-7.

26. Vreemann S, van Zelst JCM, Schlooz-Vries MS, et al. The added value of mammography in different age-groups of women with and without BRCA mutation screened with breast MRI. Breast Cancer Res. 2018;20(1):84. 
27. Heijnsdijk EAM, Warner E, Gilbert FJ, et al. Differences in natural history between breast cancers in BRCA1 and BRCA2 mutation carriers and effects of MRI screening-MRISC, MAR-

IBS, and Canadian Studies Combined. Cancer Epidemiol Biomarkers Prev. 2012;21(9):1458-68.
Publisher's Note Springer Nature remains neutral with regard to jurisdictional claims in published maps and institutional affiliations. 